\title{
A CASE OF NEUROPATHIC ARTHRITIS CAUSED BY INDIFFERENCE TO PAIN
}

\author{
H. van der Houwen, Leiden, Holland \\ From the Anna-Kliniek voor Orthopaedie, Leiden
}

Severe degenerative joint changes can be caused by lack of the protection afforded by the sense of pain. Usually the loss of pain sense is known before the joints are damaged. Recently we have investigated a man with a generalised analgesia and neuropathic arthritis of several joints, who had only a localised sensory disturbance at the age of thirteen when the first joint became affected.

\section{CASE HISTORY}

A boy, born in 1935, was seen at another hospital in 1948 because of a swollen right knee. The first radiographs showed no bony changes (Figs. 1 and 4), but after a further six months he still had a hydrarthrosis and the lateral femoral condyle was seen to be roughened (Fig. 2). The diagnosis remained obscure and an arthrotomy revealed degenerative arthritis only. A few months later, suffering from difficulty in walking because of instability of the knee, he was admitted to the neurological department of a teaching hospital; here he was observed for over three months. The senses of pain and temperature were found to be abnormal only in the right leg below the knee, although it was noted that the interpretation was difficult. Lumbar puncture and serological tests for syphilis gave normal results. On discharge he was regarded as having an arthropathia of unknown origin, and was advised to wear a protective brace, but this he refused.

In 1953 he suffered a blow on his left forearm, but continued to work. The same evening the arm was swollen and he was found to have a fracture of the ulna. Although the arm was immobilised in a plaster for six months a pseudarthrosis developed; at first the elbow joint was normal but gradually destruction occurred (Figs. 6 and 7). The arm was never painful.

In 1959 he jumped from a height of two feet and his left knee gave way, having sustained a painless compression fracture of the medial femoral condyle (Fig. 5). He was ordered complete rest but he ignored this advice, so he was admitted to this hospital. Aspiration of the knee was performed repeatedly, and up to 400 millilitres of sero-sanguinous fluid were removed each time. The right knee was now found to be completely destroyed, with the distal end of the femur lying on the medial side of the tibial condyle, and five centimetres of shortening of the leg. Considerable calcification round the joint was visible in the radiographs (Fig. 3) but, surprisingly, the knee was stable.

The lumbar spine showed scoliosis to the right, with narrowing of the lumbo-sacral disc and secondary bony changes (Fig. 8), but he had no complaints about his back. The destruction of the left elbow had increased; the radial head was dislocated and considerably displaced. The pseudarthrosis in the ulna was still present, and the bone was worn down at the fracture site (Fig. 7).

Employed as a wood sawyer, his intelligence was somewhat below the average, although he was alert. He was cooperative in the hospital, but from his history it seems that he was rather indifferent to medical advice and failed to keep his appointments. He could not remember having had headaches or abdominal pains, but he had suffered from toothache. He was sensitive to tickling and itching. He said that he could easily walk barefoot on gravel and that he could touch nettles without pain. In his youth he had suffered from inflamed toes but now there were no signs of trophic disturbances. He bore scars over the medial malleoli where he had kicked himself. 


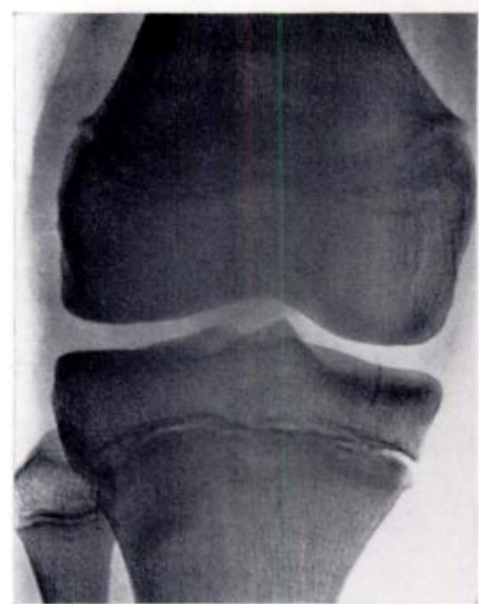

FIG. 1

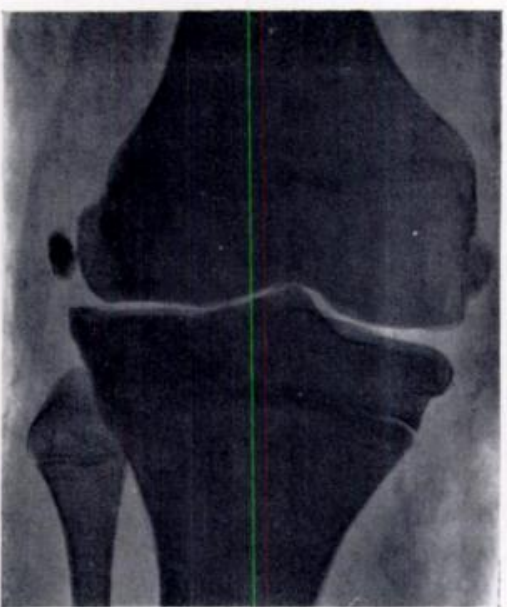

FIG. 2

Figure 1-Right knee in 1948. Figure 2-Right knee in 1949.

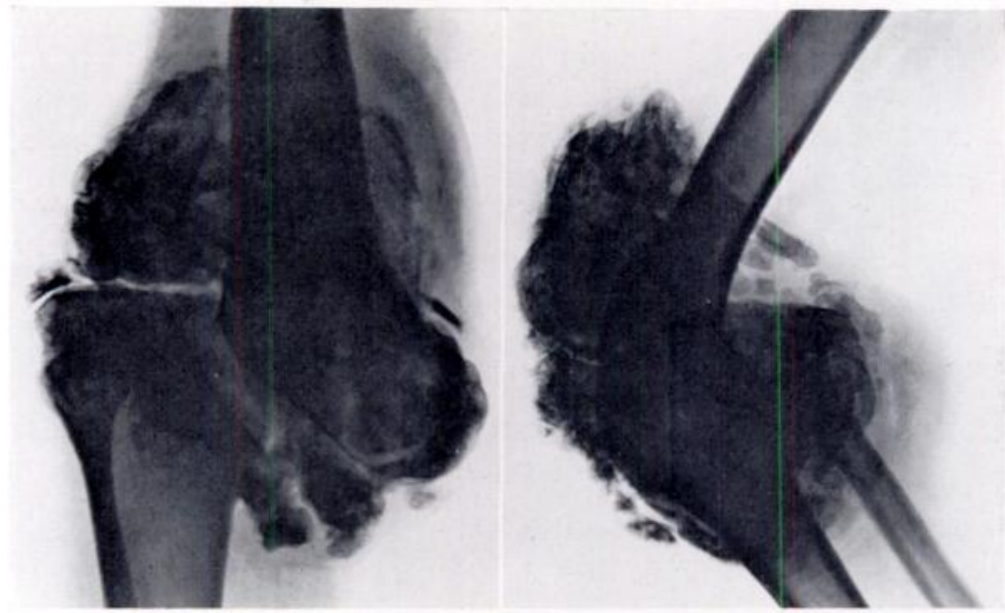

Fig. 3

Right knee in 1959.

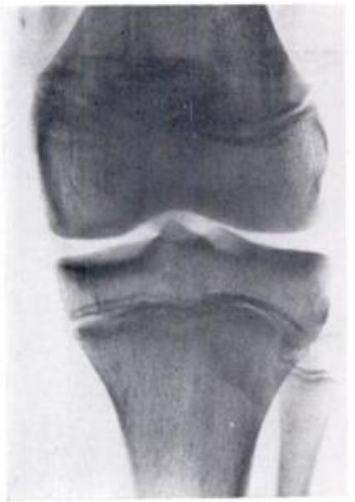

Fig. 4

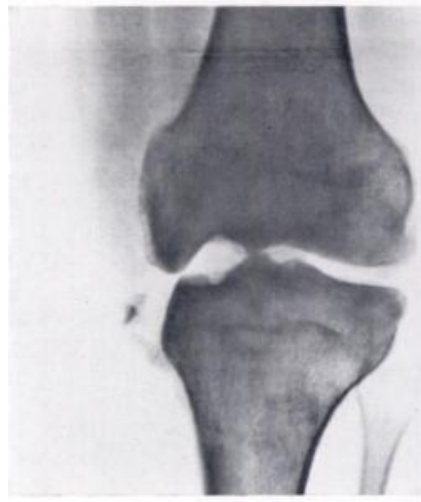

Figure 4-Left knee in 1948. Figure 5-Left knee in 1959.

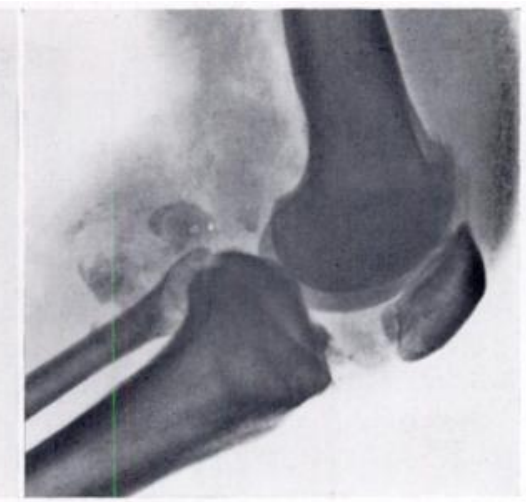

FiG. 5

vol. 43 B, NO. 2, MAY 1961 


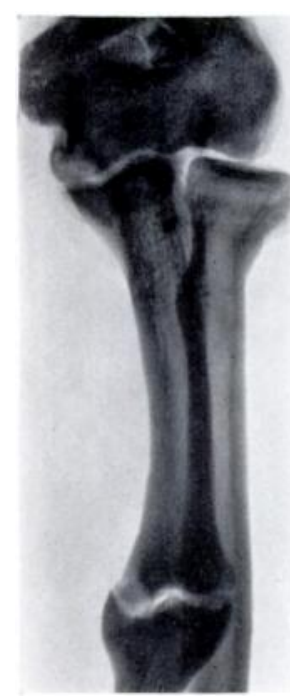

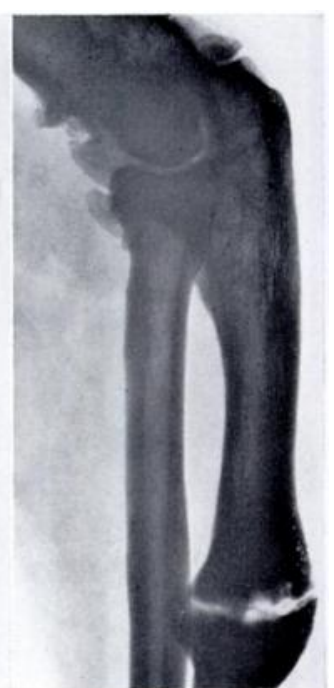

FIG. 6

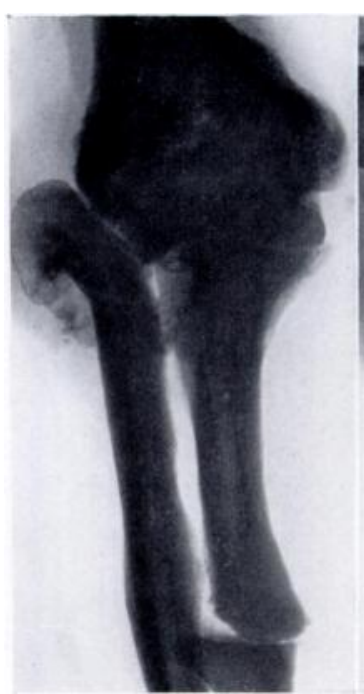

Fig. 7

Family history-The patient was the youngest of a family of nine children of whom five had died in childhood after illnesses of short duration. One sister who died in 1940 at the age of seven probably also suffered from indifference to pain as she sometimes jumped from a table and landed on her knees without signs of discomfort. She also used to scratch at little cuts which were apparently painless.

Neurological investigations-The indifference to painful stimuli was generalised, including the oral mucosa. He felt pinpricks as such, but said it was not painful. He could discriminate between sharp and blunt, but would make some mistakes when the point of a pin was applied lightly or when the head was applied firmly. Pulling on

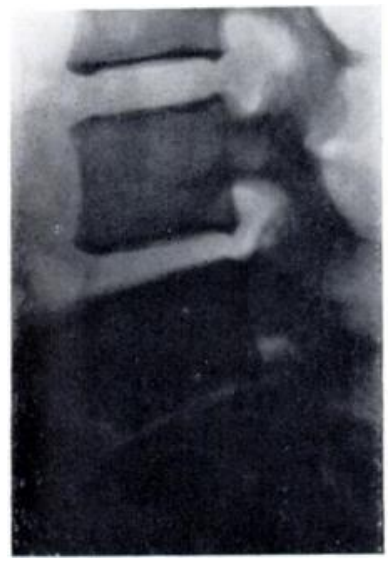

FIG. 8

Lumbar spine in 1959. his hairs, muscle-ischaemia-five minutes at a pressure of 180 millimetres of mercury - and severe electrical stimulation were endured with a smile. Pinching the calcaneal tendon and the testes (as well as aspirating the knee with a thick needle) were not painful, and produced no dilation of the pupils. A ridge in the plaster cast immobilising his left knee caused an excoriation which was hardly noticed by the patient.

The pupils showed a tonic contraction to light, corneal sensation was diminished and the reflex was sluggish; touching the right cornea was less unpleasant than the left. Vision, the visual fields, hearing and smell were normal. There was no wasting or fasciculation of muscles, in which tone and power were normal, the abdominal reflexes were present and equal, and the tendon reflexes were normal except in the right knee which may have been because of the deformity of the joint; no other abnormal reflexes were found. Light touch, two-point discrimination, vibration and postural sense and stereognosis were normal. The patient correctly located the point of stimulation and there was no confusion between right and left. Temperature sense was undisturbed, with discrimination between slight differences in temperature (he had never suffered painless burns and he was careful with heat). The electro-encephalograph was normal.

Other investigations-The alkaline phosphatase was slightly raised (18,2 King-Armstrong units); the blood-Kolmer and V.D.R.L.* reactions were negative.

* The standard cardiolipin test of the United States Venereal Diseases Reference Laboratory. 


\section{DISCUSSION}

The severe joint changes in this patient were occasioned by an isolated loss of pain sensation. Trophic disturbances are not a part of this condition and are apparently not a requisite for the development of neuropathic joints. According to Silverman and Gilden (1959) forty-six such cases have been published; when this analgesia is discovered in childhood it is called congenital indifference to pain. It is remarkable that in this patient the sensory defect was found so late. Even on thinking back his parents can remember only a few occasions on which he may have shown more than usual insensitivity to pain.

The lesion is thought to be somewhere in the thalamic region of the brain, but there have been no reports on the pathology of this condition. In hereditary sensory radicular neuropathy, in which there are also defects of other senses, lesions have been found in the dorsal root ganglia with atrophy of the ascending tracts.

The differential diagnosis of a neuropathic joint includes tabes dorsalis, syringomyelia and diabetic neuritis. Analgesic states can be found in mental retardation, hysteria and schizophrenia. Schilder and Stengel (1931) described asymbolia for pain caused by an acquired lesion in the posterior parietal region of the dominant hemisphere. A similar state can be caused by double division of the spino-thalamic tract and by frontal leucotomy. The other affections of bone seen in patients with indifference to pain are osteomyelitis and deformities due to malunited fractures.

\section{SUMMARY}

1. A twenty-five-year-old man who developed neuropathic arthritis because of indifference to pain is described. He presented at the age of thirteen with degenerative changes in the 1 ight knee with analgesia only in the right leg below the knee.

2. A painless fracture of the ulna developed non-union and was associated with a neuropathic arthritis of the elbow joint.

3. Later the other knee and the lumbo-sacral spine became affected. The analgesia became generalised with all other senses staying intact. Apart from tonic pupillary reactions and diminished corneal sensibility no other neurological signs could be found.

4. A deceased sister may also have suffered from the same condition.

I am very grateful to Dr J. D. Mulder, Dr F. Duyfjes, and to Dr F. Steenwinkel, of the Anna-Kliniek, for their helpful criticism and advice.

\section{REFERENCES}

Cambier, J., and Lefebvre, J. P. (1959): L'indifférence congénitale à la douleur. Presse Médicale, 67, 1,551. Critchley, M. (1956): Congenital Indifference to Pain. Annals of Internal Medicine, 45, 737.

Fanconi, G., and Ferrazzini, F. (1957): Kongenitale Analgie. Helvetica Paediatrica Acta, 12, 79.

JÉQuier, M., and Deller, M. (1956): L'indifférence congénitale à la douleur. Confinia Neurologica, 16, 207. Jewesbury, E. C. O. (1951): Insensitivity to Pain. Brain, 74, 336.

Murray, R. O. (1957): Congenital Indifference to Pain with Special Reference to Skeletal Changes. British Journal of Radiology, N.S. 30, 2.

OrtiZ de Zarate, J. C. (1955): Analgésie généralisée congénitale. Encéphale, 44, 414.

Petrie, J. G. (1953): A Case of Progressive Joint Disorders Caused by Insensitivity to Pain. Journal of Bone and Joint Surgery, 35-B, 399.

Schilder, P., and Stengel, E. (1931): Asymbolia for Pain. Archives of Neurology and Psychiatry, 25, 598.

Silverman, F. N., and Gilden, J. J. (1959): Congenital Insensitivity to Pain: a Neurologic Syndrome with Bizarre Skeletal Lesions. Radiology, 72, 176. 